\title{
Impact of Stress on Teachers' Productivity as an Important Factor in the Increase of Educational Quality
}

\author{
Prof. Assoc. Dr. Xhevdet Zekaj
}

Lecturer at "Aleksander Xhuvani" University xhzeka@yahoo.com

Doi:10.5901/mjss.2015.v6n2s2p245

\begin{abstract}
National education system serves as a serving sector which will enrich future Albanian citizens with the necessaries knowledge, skill and bravery, educated and devoted to accomplish the national economic and developmental plan. This system, tending to accomplish national needs of labor market and the socio-cultural aspirates of people, is represented as being conditional for economical growth and stable development of the country. Therefore, this commitment is companioned with stress to every actor participating on this growing work, and not only. Despite the stress more and more wounds and phenomena are opened in our society. The aim of this study is to introduce a connection, cause- effect at work and to workers productivity, factors that influence, political intervention, economical, social and integrated factors. Watching the fact that life has changed and life rhythm that people do work and live has made the same thing, in this case they do fee more pressure and stress in their daily life and work. A very dangerous potential risk of people, is to find a balance between work and life. As it is known, stress is one of the most inflectional factors of a lot different problems and disease, but also a factor which determine the success of failure of an organization. As a very negative factor, it is responsible for workers' passivity at work, and as a consequence diminish their performance and productivity. Factors such as: demands, check, relationship, change, role and support are potential factors for stress at work. A serious problem would be if the stress of a certain branch would spread in other ones and this would make it more difficult to handle it. Lately there is another factor called "culture" which is defines as "organization' culture and the way they deal with stress at work". On this work it has been shown Albanian and world experience with some endings, options and recommendation to avoid stress and ensure quality on the educational system.
\end{abstract}

Keywords: Worker, Stress Productivity, Impact, Productivity Level, Education

\section{Introduction}

Stress has increased inevitably lately, which makes us raise the question: what is happening to our society that causes the high level of stress? Why stress is so evident and alarming for the education system? It is known that stress has extraordinary influence on individuals that are positioned on the top or the bottom of the social-economical scale .The term stress is spread out so widely that cannot be excluded from family or professional life, for these reasons the stress issue cannot be ignored, and we detected this on all education institutions and actors that we have met, interviewed or discussed with.

Contemporary definitions view it as a personal experience, caused from demands over the individual and from his perception of the qualities that he owns in order to fulfill this demands. Stress at work happens mostly when there is a contradict between the demands from work with the sources and the ability of the employee to adjust with them. There are identified six factors, as potential catalytic of occupational stress: demand, control, relationships, change, role and support. Another factor of potential risk is the balance between life and work. This situation can become a vicious circle if stress encountered in one life's field will spread out on every aspect of someone's life and make the stress' battle a lot more difficult. In the last years is added the factor "culture", that is paraphrased as "organization's culture and the way it treats and manages stress at work" (De Vos, A.S.\&Fouchè,C.B. 1998a).

Some factors that influence negatively or increase the level of stress:

1. Law in education that changes constantly

2. Crisis and reforms and education system

3. Corruptive and political recruitment in the education system

4. Curriculum and additional materials especially alternate textbooks

5. Political influence and militarization in the educational hierarchies

6. Economical evaluation, low wages, career, qualification, environment, the fulfillment or failure of Bologna 
treaty, multi-employment and so on

7. The extra extended transition in the country

The term "stress" is part of the everyday vocabulary in our country for most people, but the real meaning and its dimension remains unclear. Even though multiple events in the workplace might be considered as contribution to stress, that does not make the only reason. The development and the increase of stress can be seen as related with specific historical events also with economical factors. An increase in illnesses related to stress might be because off an increase of consciousness about stress that has started to apply in the last years, suggesting that stress is a result of that historic contest, even of the everyday ideological politics. People feel that they are under higher levels of stress especially in the workplace, and these people are specially employees with the highest status, but even some with low status. The organizational demands might be very stressful if they require extended and not desirable rules, when are associated with changes on other aspects of employees' lives, when they are unexpected and obligatory, and when the employees do not have the right tools or when they are ineffective(KLATT et al.,1985). Organizational resources off stress in the workplace include factors like the complexity of organizational technology, complex politics and organizational procedures, poor conditions in the workplace, changes of structure and cultural organization. (Gerberet al., 1999).

\subsection{Purpose of the study}

The purpose of this study is: to highlight factors that cause stress in education workers, define the stress level, to identify if the stress factor affects productivity, and to come up with conclusions that will solve this problems.

\subsection{Study goals}

$>$ Gather information related to the influence of stress at Education workers productivity, referring to previous studies in this field;

$>$ Investigate on factors of stress that influence over education workers. Identify their stress level;

$>$ Getting informed in practices used in the workplace Wednesday employee is encountering problems and feels under pressure;

This study was based on 80 teachers in different schools;

The interviewed are picked randomly;

The collection of information for this study is realized through two main instruments, which are:

- (Job stress inventory) Rodney L. Lowman and the organizational consulting centers staff

- $\quad$ The instrument " De Vos" and "Fouche" 2006, the productivity

\subsection{Hypothesis}

1. There exists very high levels of stress on educational workers

2. High levels of stress on employees are related to low levels of productivity

3. High levels of stress on education workers are related with high levels of productivity in education.

\section{Literature Review. The Stress in the Work Place / Education System}

Stress is a part of our everyday life. The causes of stress generally are our everyday demands, which cause anxiety when people have difficulties facing them.

Johns (1996) defines the stress as a psychological reaction towards the continuous demands of a stressor, who has got the potential to put pressure and anxiety on other people.

Robbins (1996) defines stress as an interaction between a person and the environment which seek adaptation, while Jozefi (2000) defines stress as a demand which is upon the capacity of the power of the body and mind of a person.

Based on these definitions, we can come to the conclusion that stress can prevail in the work place if the demands overlap the capacities of the employee.

Apart from the recent changes in the education system, the working condition are a very serious problem. Besides the high level of stress and the intensification of the demands, the employees of the education system come across a wide range of stressful factors in their work. We can mention two types of potentially harmful conditions at the work place: the risks in the work place and the stressful factors related to work. 
The first include the environment, the rooms, the lack of materials, of labs, of proper spaces, noises etc, while the second include the pressure of time, working overtime, the responsibilities, the monotony etc (Paoli and Merille 2000)

\subsection{Causes of work-related stress}

Although the way each person experiences stress in a very subjective way, it is made obvious that there are a series of factors which are identified as potential causes of stress related to work. They are directly related to the importance and difficulties of a certain job. However, HSE has identified six factors that can lead to work related stress if they are not managed properly.

- Demands: Employees indicate that they are able to cope with the demands of their jobs. These demands are work conditions, shifts, long or isolated working hours and the workload.

- Control: It has to do with the level of independency and the effect of control on the employee's work. Less control to the work means less stress at work.

- Support: Employees indicate that they need to receive adequate information and support from their colleagues and superiors. Employees who work long hours alone and without support usually have difficulties coping with all the work load and home load at a time, especially if they have children to look after.

- Relationships: Employees indicate that they might be subjected to unacceptable behaviors, e.g. bullying at work, teasing or different conflicts. These and the relationship they create with the boss and the colleagues are closely related to stress.

- Role: Stress may increase when an individual does not have a clear understanding of its role in the organization, when there is a conflict or ambiguity between the roles concerning the position and what are his/her responsibilities related to others.

- Change: The way a change is presented and communicated to the employee, may affect stress levels, and even if is a small scale change it may increase the pressure on employees.

Some other factors are:

- Long distances from work

- Demographic factors

- Transportation

- The number of children in class

- Educational curricula

- Frequent organizational changes

- Family commitments

Also, there are some more specific psychological factors to be considered, including past experience and personality qualities. In conclusion, stress levels also depend on what a person perceives as threatening or challenging and if he/she believes that he/she is able to cope with it. All these social and psychological variables can profoundly affect the way individual experience stress, so, stress seems to be very personalized.

\subsection{Organizational sources of stress}

Organizational demands can be stressful if they require extensive or unwanted adjustment, when accompanied by changes in other parts of employees' lives, when they are unexpected and forced on employees as well as when the employees' coping mechanisms are absent or ineffective (Klatt et al., 1985).

Organizational sources of occupational stress include factors such as complexity of the organizational technology, complex policies and procedures, poor working conditions, career transitions such as promotions and relocations, change in organizational structure and organizational culture (Gerber et al., 1999). Poor professional communication, extremes of management style, working with an inexperienced staff, lack of clarity and agreement about organizational values and goals, lack of consideration for the individual within the organization as well as an uncomfortable working environment have all been identified as organizational sources of stress (Grobler et al., 2002).

Whatever its source, excessive work stress has serious consequences for the employee, for their productivity and for the students as well as it influences the quality of education in general. Under stress teachers, would never be able to give their best at working with students. (Driskell, Johnston \& Salas, 2001). 


\subsection{Stress Can Affect Productivity}

Mathis and Jackson (2000:75) suggested that to measure organizational human resource productivity we have to consider labor cost for one unit, or the total labor cost per unit of productivity. The authors further stated that an individual performance depends on the personality and two people cannot react in the same way towards stress. For example, personalities of a type A are people who feel determined and they want to be always on time to meet deadlines, usually they are the people who put themselves under more stress than others (Desseler 2000:586). This is also reinforced by Bowin and Harvey (2001:369) who stated that people cannot fully divide their work from their personal life. So, the way people react and deal with stress at work is a complex problem.

According to Blumenthal (2003:7) an inverted U-type curve has been used to illustrate the effect stress has on performance. It can be shown that, as stress increases, so does the performance. However if stress continues to increase beyond an optimal point, performance will peak and start to decline. This shows that stress is necessary to improve performance but once it reaches a level that will create discomfort, it might for sure be harmful and have the counter effect.

Productivity is lower when stress is not managed properly; being absent at workplace and medical compensation are in this way higher and Garrison and Bly (1997:420) further stated that the job is special just because most of our time is spent at work. To achieve the best performance, stress must be managed effectively, and negative effects of stress should be minimized. Garrison and Bly (997:420)

\section{Methodology}

This correlation study aims to investigate the relationship or the relation between two variables. Variables we are dealing with are independent:

(1) Levels of stress among the education employees. It will be measured by Level of Stress in the Workplace.

(2) The productivity of education employee. It will be measured by Level of Productivity in the Workplace.

In this study participated 80 teachers from Tirana. The subjects were 40 males and 40 females. They were chosen randomly and before delivering the questionnaires, they were informed about the scope and the nature of this study. They were also supported for any inconvenience they might face during fulfilling the questionnaire.

To collect the data for the study, two basic instruments were used, and they are:

$>$ (Job stress inventory) Rodney L. Lowman and the Organizational Consulting Center Staff

$>$ The $1^{\text {st }}$ Instrument (De Vos'"' and"'" Fouche 2006) for productivity.

\subsection{Job Stress Inventory}

\section{(RodneyL.Lowman and the Organizational Consulting Center Staff)}

The grading for each one is as follows:

These instruments are also used in other studies in the psychology field.

The advantage of these instruments is to measure the level of stress, whether it is high or low and to measure productivity, whether it is high or not. Also by using such instruments we can find out valuable data about the level of stress and the impact stress has on education employees. We have always respected their confidentiality and anonymity.

It can be considered as a disadvantage the fact that these instruments are adopted from foreign studies and the process of translation and adaptation to Albanian environment and language makes it difficult to interpret.

The study is always careful as far as as ethical issues are associated with:

a) informing the subject of the study and taking his/her consent

Subjects were initially informed about the study and if they agreed, they were informed in detail about the purpose, conditions and the study method that will be used.

b) confidentiality

Subjects also were informed that whatever data collected from them will be used only for research purposes and that their anonymity and confidentiality will be totally respected.

c) avoidance of any possible fraud or revealing of data

Subjects were introduced to the purpose of the study, without using it for other bad purposes, and they were also assured that its results will be available and sent to the Social Sciences Faculty, Tirana. 


\section{Conclusions and Recommendations}

$>$ To stop militancy and political influence in the education system.

> The educational system should be free of stress caused due to the reforms that are not productive and very fragile most of the time.

$>$ To fight corruption in the education system.

> To deal with great responsibility with the curricula.

$>$ The staff should be trained about how to deal with stress at the work place

$>$ To give support to the employees that have a low level of social support

\section{Questionnaire's reliability}

The questionnaire has a high reliability

\section{Reliability of the questionnaire}

The questionnaire has a high level of reliability Cronbach's Alpha=947

Table 1: Reliability Statistics

\begin{tabular}{|c|c|c|}
\hline Cronbach's Alpha & Cronbach's Alpha Based on Standardized Items & N of Items \\
\hline .947 & .947 & 19 \\
\hline
\end{tabular}

As it is shown the mean in the first questionnaire is high: Std Dev 15.79

Table 1.1: Scale Statistics

\begin{tabular}{|c|c|c|c|}
\hline Mean & Variance & Std. Deviation & N of Items \\
\hline 52.1864 & 249.430 & 15.79336 & 19 \\
\hline
\end{tabular}

Even the second questionnaire has a high level of reliability Cronbach's Alpha $=.947$

Table 1.2: Reliability Statistics

\begin{tabular}{|c|c|c|}
\hline Cronbach's Alpha & Cronbach's Alpha Based on Standardized Items & N of Items \\
\hline .867 & .867 & 10 \\
\hline
\end{tabular}

As it is shown in the next table the mean is high (45.33) in the first questionaire; Std Dev 13.27

Table 1.3: Scale Statistics

\begin{tabular}{|c|c|c|c|}
\hline Mean & Variance & Std. Deviation & N of Items \\
\hline 45.3390 & 8.573 & 13.2793 & 10 \\
\hline
\end{tabular}

These are the tables about the demographic data of the employees

\section{Frequencies}

\section{The data taken from the questionnaire 1}

Here is the data of half of the participants. 
As it is shown almost $81 \%$ of the participants declare that they face high or an avarage level of stress, and only $18 \%$ declares a low level of stress.

Table 2.2:

\begin{tabular}{|c|c|c|}
\hline $\mathrm{N}$ & Category & Percent \\
\hline 20 & $<40$ pike & $18.64 \%$ \\
\hline 60 & $>40$ pike & $81.35 \%$ \\
\hline
\end{tabular}

Figure 2.3:
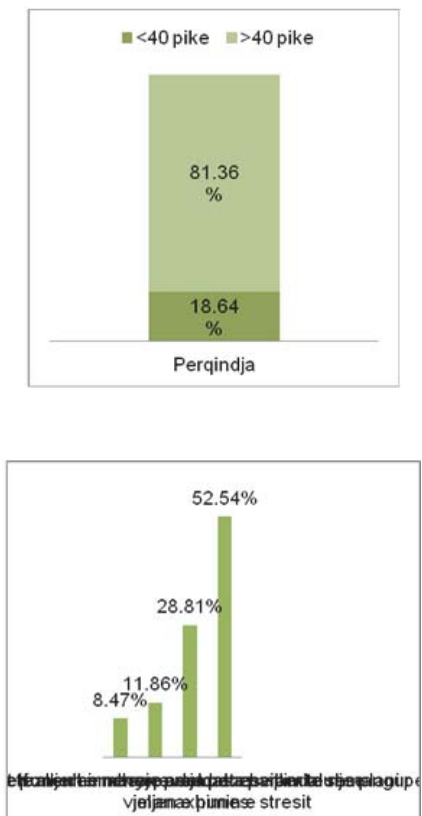

Figure 2.4:

The tables and the percentages indicate that more than $50 \%$ of the participants need to develop a plan for the management of the stress

\section{The results of the second questionnaire}

Table 2.5:

\begin{tabular}{|c|c|c|}
\hline $\mathrm{N}$ & Category & Percent \\
\hline 21 & $<15$ pike & $29.15 \%$ \\
\hline 59 & $>15$ pike & $70.84 \%$ \\
\hline
\end{tabular}

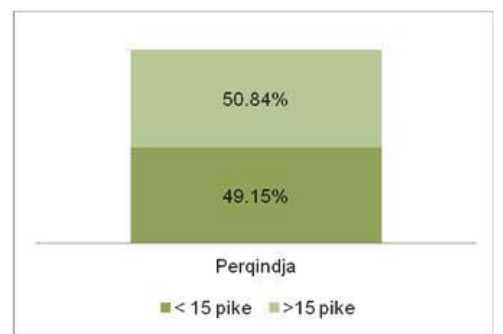

The data taken from the second questionnaire indicate that for almost $70 \%$ of the partecipants the stress they face at work influences in their productivity while at work. 


\section{References}

1. Bickford, M. (2005). Stress in the Workplace: A General Overview of the Causes, the Effects, and the Solutions. Canadian Mental Health Association, Newfoundland and Labrador Division.

2. Chartered Society of Physiotherapy, Employment Relations \& Union Services: Health \& Safety

3. Cox T, Stress, Basingstoke, Macmillan, 1978

4. Grimshaw, J. (1999). Employment and health: Psychosocial stress in the workplace. London: The British Library.

5. International Labour Organization. (2001). what is workplace stress?

6. Lazarus R S and Folkman S, Stress, Appraisal, and Coping, New York, Springer, 1984

7. Lefcourt, H.M. (1976). Locus of Control: Current Trends in Theory and Research. NJ: Lawrence Erlbaum Associates.

8. MIND, 'Stress and mental health in the workplace', Mindweek report, May 2005

9. National Institute for Occupational Safety and Health, Stress at Work, U.S. Department of Health and Human Services, 1999

10. Pollock K, 'On the nature of social stress: production of a modern mythology', Social Science and Medicine, Vol. 26 No. 3, 1988

11. TUC, Focus on Health and Safety, Trade Union Trends Survey 04/03, 2004.

12. Weiner, B., ed. (1974). Achievement Motivation and Attribution Theory. NY: General Learning Press.

13. Wichert, I. (2002). Job insecurity and work intensification: The effects on health and Wellbeing.

Schultz, D.P., Schultz, S.E. (2005). Theories of Personality (8th ed.). Wadsworth: Thomson 